\title{
Effects of a dietary excess of leucine on the metabolism of tryptophan in the rat: a mechanism for the pellagragenic action of leucine
}

\author{
BY DAVID A. BENDER \\ Courtauld Institute of Biochemistry, The Middlesex Hospital Medical School, \\ London WIP $7 P N$
}

(Received 19 October 1982-Accepted 24 January 1983)

1. In order to investigate the mechanism of the pellagragenic action of excess dietary leucine, rats were fed on diets providing a minimally-adequate amount of tryptophan, with no preformed niacin, with and without the addition of $15 \mathrm{~g}$ leucine $/ \mathrm{kg}$ diet. This amount of leucine in the diet has been demonstrated previously to lead to depletion of blood and liver nicotinamide nucleotides. The metabolism of tryptophan was assessed by measurement of the production of ${ }^{14} \mathrm{CO}_{2}$ after the administration of [methylene- $\left.{ }^{14} \mathrm{C}\right]$ tryptophan to estimate the activity of kynureninase (L-kynurenine hydrolase, EC 3.7.1.3) and [benzene ring U-14C]tryptophan to estimate the activity of picolinate carboxylase (aminocarboxymuconate semialdehyde decarboxylase, EC 4.1.1.45).

2. A dietary excess of leucine led to inhibition of kynureninase and increased the activity of picolinate carboxylase. Both of these effects would result in a reduction in the rate of metabolism of acroleylaminofumarate (aminocarboxymuconate semialdehyde) to quinolinic acid and hence to nicotinamide nucleotides. These two effects provide an explanation for the pellagragenic effect of a dietary excess of leucine in animals that are wholly or partly reliant on endogenous synthesis from tryptophan to meet their requirements for nicotinamide nucleotides, and presumably also explain the pellagragenic effect of a dietary excess of leucine in man.

Gopalan \& Srikantia (1960) suggested that among people whose dietary staple is jowar (Sorghum vulgare) a major factor in the development of pellagra might be the relative excess of leucine in the protein of the cereal, since it provides more tryptophan than does maize protein, and almost as much as rice, a staple that is not associated with pellagra. A previous report from this laboratory (Magboul \& Bender, 1983) has confirmed the observations of Gopalan \& Srikantia (1960), Ghafoorunissa \& Narasinga Rao (1973) and Krishnaswamy \& Bapu Rao (1978) that a dietary excess of leucine may indeed be pellagragenic. Feeding rats on a maize-based diet providing just enough tryptophan to permit minimally-adequate synthesis of nicotinamide nucleotides, together with $15 \mathrm{~g}$ of $\mathrm{L}-\mathrm{leucine} / \mathrm{kg}$ diet, led to a significant depletion of tissue nicotinamide nucleotides. This effect was only apparent when the animals were wholly or partly dependent on synthesis of the nucleotides from tryptophan; when the diet provided an adequate amount of preformed niacin, the addition of leucine had no effect on tissue concentrations of nucleotides. It is thus apparent that a dietary excess of leucine has an effect on the oxidative metabolism of tryptophan, such as to reduce the synthesis of nicotinamide nucleotides. Three possible sites of action have been identified by various workers: (1) Ghafoorunissa \& Narasinga Rao (1973) showed that in animals fed on diets providing as much as $30 \mathrm{~g} \mathrm{~L}$-leucine $/ \mathrm{kg}$, there was increased total oxidation of tryptophan to carbon dioxide, an effect that they ascribed to increased activity of picolinate carboxylase (aminocarboxymuconate semialdehyde decarboxylase, EC 4.1.1.45). This would result in increased catabolism of acroleylaminofumarate (aminocarboxymuconate semialdehyde) and hence permit less of this intermediate of tryptophan metabolism to accumulate and undergo the non-enzymic cyclization to quinolinate, the immediate precursor of the nicotinamide nucleotides. (2) Krishnaswamy \& Bapu Rao (1978) suggested that as well as this activation of picolinate carboxylase, a dietary excess of leucine might lead to reduced activity of quinolinate phosphoribosyltransferase (nicotinate 


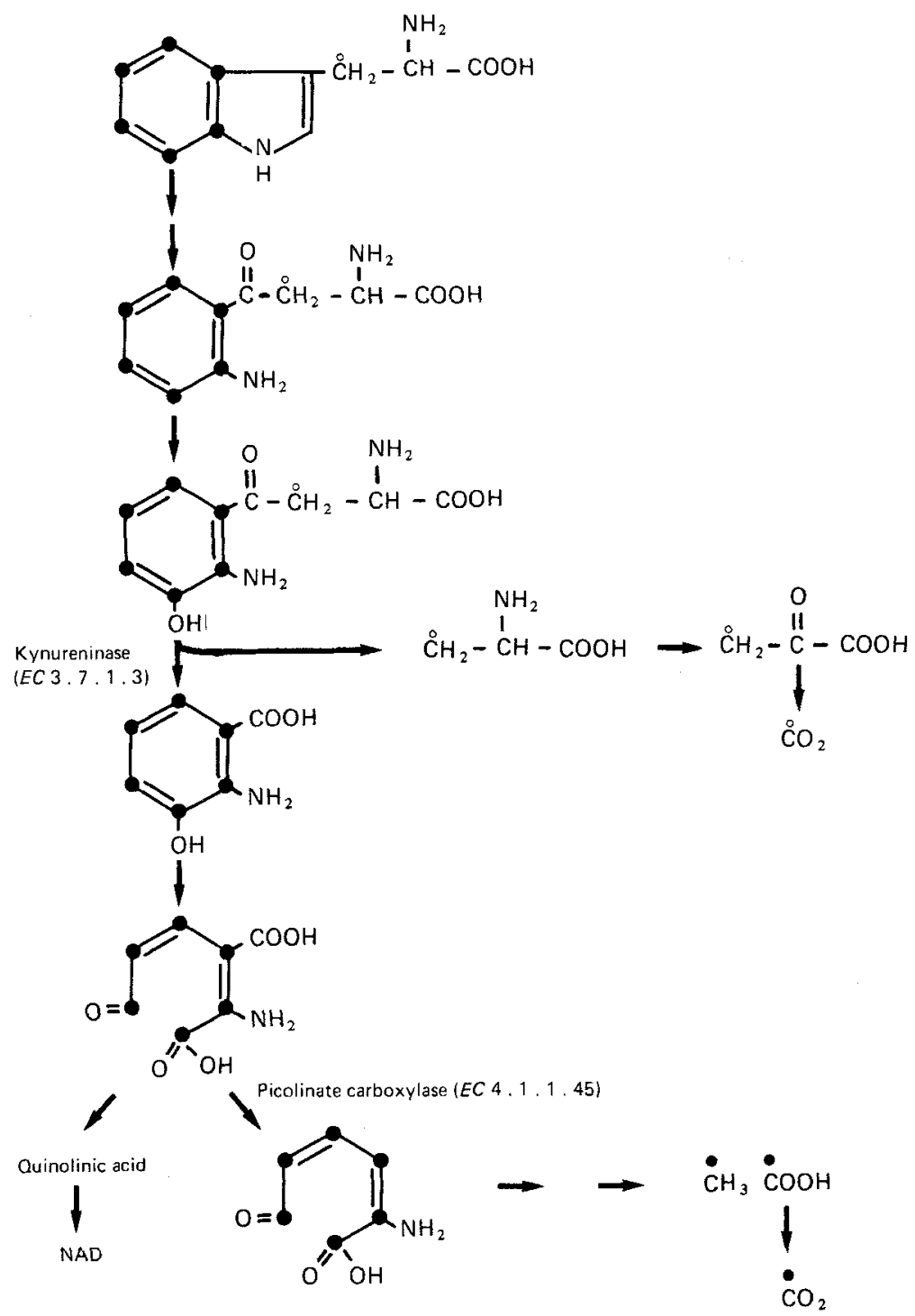

Fig. 1. The release of ${ }^{14} \mathrm{C}$-labelled carbon dioxide from $\left[{ }^{14} \mathrm{C}\right]$ tryptophan. (O), $[$ Methylene-14 $]$ tryptophan; (O), [benzene ring $\left.\mathrm{U}^{14} \mathrm{C}\right]$ tryptophan.

nucleotide: pyrophosphate phosphoribosyltransferase (carboxylating) EC 2.4.2.19), which would reduce yet further the formation of nicotinamide nucleotides from tryptophan. However, it is unlikely that anything less than a very considerable inhibition of quinolinate phosphoribosyltransferase would have any significant effect on the synthesis of nicotinamide nucleotides, since this enzyme seems to be present in the liver at a very much greater activity than is required for metabolism of the quinolinic acid that is formed from tryptophan, even after the administration of relatively large amounts of amino acid (Bender et al. 1982). Magboul \& Bender (1983) were unable to demonstrate any effect of leucine on the activity of this enzyme, either after feeding the amino acid to rats, or when it was added to liver homogenates. (3) Magboul \& Bender (1983) suggested that inhibition of kynureninase 
(L-kynurenine hydrolase, EC 3.7.1.3) might be important in the pellagragenic action of a dietary excess of leucine. They showed that the addition of leucine to liver homogenates led to a significant competitive inhibition of this enzyme. There was no significant difference in the activity of kynureninase in liver samples between animals fed on diets high in leucine and control diets; this was interpreted as being the result of both the reversible competitive nature of the inhibition and the method of assay used, which involved both some amount of dilution of the tissue (and hence of the inhibitor) and also the use of a saturating concentration of kynurenine as substrate, which would reverse the inhibition. They demonstrated an increase in the urinary excretion of kynurenine by animals fed on the high-leucine diet, which was interpreted as evidence of inhibition of kynureninase in vivo.

The object of the present study was to determine whether, and to what extent, a high-leucine diet fed to rats affects the metabolism of tryptophan, and especially the activities of kynureninase and picolinate carboxylase, in vivo. This was assessed by the administration of two positional isomers of $\left[{ }^{14} \mathrm{C}\right]$ trytophan, and measurement of the production of ${ }^{14} \mathrm{CO}_{2}$; the label from $\left[\right.$ methylene $\left.-{ }^{14} \mathrm{C}\right]$ tryptophan will be released by the action of kynureninase, and that from [benzene ring $\mathrm{U}-{ }^{14} \mathrm{C}$ ]tryptophan by the action of picolinate carboxylase. In each case, respiratory ${ }^{14} \mathrm{CO}_{2}$ is one of the major products (Smith et al. 1980). The pathway concerned is shown in Fig. 1.

The results show that a high dietary intake of leucine both reduces the activity of kynureninase and increases the activity of picolinate carboxylase. The result of these two effects will be a considerable reduction in the synthesis of nicotinamide nucleotides from tryptophan, and this presumably explains the pellagragenic effect of a high-leucine diet.

METHODS

Male Wistar rats, bred in the Courtauld Institute of Biochemistry, were weaned at $21 \mathrm{~d}$ after birth on to the maize-gelatine-sucrose diet that has been described previously (Magboul \& Bender, 1983), providing no preformed niacin and just enough tryptophan to permit synthesis of nicotinamide nucleotides and limited growth (1030 $\mathrm{mg}$ L-tryptophan $/ \mathrm{kg}$ diet). L-Leucine $(15 \mathrm{~g} / \mathrm{kg}$ diet $)$ was added to the experimental diet at the expense of sucrose. Previous studies (Magboul \& Bender, 1983) have shown that such a high-leucine diet leads to significant depletion of blood and liver nicotinamide nucleotides after 6-7 weeks; in the present study animals were maintained on the diets for 5 weeks, at which time there was significant growth retardation in the experimental group, but relatively little effect on the tissue content of nicotinamide nucleotides.

Each animal received an intraperitoneal injection of $50 \mathrm{mg} \mathrm{L}-\left[{ }^{14} \mathrm{C}\right]$ tryptophan at a specific radioactivity of $0.1 \mathrm{mCi} / \mathrm{mmol}$, using either $\mathrm{L}-\left[\right.$ methylene $\left.{ }^{-14} \mathrm{C}\right]$ tryptophan or $\mathrm{L}-[$ benzene ring U- $\left.{ }^{14} \mathrm{C}\right]$ tryptophan dissolved in $1 \mathrm{ml} 0.15 \mathrm{M}$-sodium chloride. The injections were given at 12.30 hours, the animals having been deprived of food, but not water, since 08.30 hours. Animals were then placed individually in glass vessels which were sealed; air was passed in from a small compressor and the air leaving the vessel was bubbled through a solution of Hyamine hydroxide ( $50 \mathrm{~g} / 1$ methanol-propan-2-ol $(1: 1, \mathrm{v} / \mathrm{v})$ ) to absorb the $\mathrm{CO}_{2}$. Every $10 \mathrm{~min}$ the compressor was stopped for about $1 \mathrm{~min}$ and the Hyamine hydroxide solution in each collecting vessel was changed; collection of $\mathrm{CO}_{2}$ continued for $4 \mathrm{~h}$. The solution of $\mathrm{CO}_{2}$ in Hyamine hydroxide was washed into scintillation-counter vials with a total of $10 \mathrm{ml}$ of a solution of PPO (3 g/l) and POPOP $(0 \cdot 3 \mathrm{~g} / 1)$ in toluene and radioactivity was measured using a Beckman LS 7500 liquid-scintillation counter equipped with automatic quench correction.

Mean production of ${ }^{14} \mathrm{CO}_{2}$ over each $10 \mathrm{~min}$ interval was plotted and the best-fitting curves were estimated by inspection. The first-order rate-constant for the decay of ${ }^{14} \mathrm{CO}_{2}$ production $(k)$ and the half-time of the decay of production from the peak were calculated 
from the gradient of the (linear) plot of $\log _{10}$ (radioactivity) $v$. time; this line and the standard error of the gradient were calculated by unweighted least squares regression.

Both positional isomers of $\left[{ }^{14} \mathrm{C}\right]$ tryptophan were purchased from Amersham International (Amersham, Bucks). [Methylene $\left.-{ }^{14} \mathrm{C}\right]$ tryptophan was available as the $\mathrm{L}$-enantiomer, and this was used without further purification. However, [benzene ring $\left.\mathrm{U}-{ }^{14} \mathrm{C}\right]$ tryptophan was available only as the racemic mixture. This was resolved by exploiting the stereo-specific binding of tryptophan to serum albumin, by the following modification of the method of Stewart \& Doherty (1973), using immobilized bovine serum albumin. Cyanogen bromideactivated CH Sepharose 4B (Pharmacia Ltd) was swollen in $1 \mathrm{mM}$-hydrochloric acid and was then washed on a sintered-glass disk with $1 \mathrm{~mm}-\mathrm{HCl}$. An amount of the swollen gel equivalent to $0.3 \mathrm{~g}$ of the dry material was then mixed with a solution of $500 \mathrm{mg}$ bovine serum albumin (Cohn fraction V; Armour-Pharmaceutical Co. Ltd) in $10 \mathrm{ml} 0.2 \mathrm{M}$-sodium bicarbonate, $\mathrm{pH} 8 \cdot 0$, for $1 \mathrm{~h}$, with gentle end-over-end mixing. The gel was then recovered on a sintered-glass disk and was washed under gentle suction with $20 \mathrm{ml} 0.2 \mathrm{M}-\mathrm{NaHCO}_{3}$, $\mathrm{pH} 8.0 ; 100 \mathrm{ml}$ Tris-hydrochloride, $\mathrm{pH} 8.0$, containing $0.5 \mathrm{M}-\mathrm{NaCl} ; 100 \mathrm{ml} 0.05 \mathrm{M}$-sodium acetate buffer, $\mathrm{pH} 4 \cdot 0$, containing $0.5 \mathrm{M}-\mathrm{NaCl}$; and finally $100 \mathrm{ml} 0.1 \mathrm{M}$-sodium borate buffer, $\mathrm{pH} 9 \cdot 2$. The gel was stored for up to $3 \mathrm{~d}$ at $4^{\circ}$ in this last buffer. For the resolution of DL- $\left[{ }^{14} \mathrm{C}\right]$ tryptophan, a $30 \mathrm{~mm}$ high column of the Sepharose-albumin gel was prepared in a pasteur pipette plugged at the constriction with glass wool. The column was washed

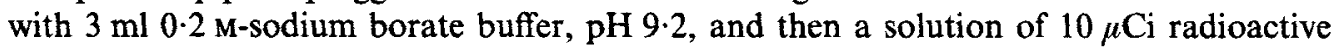
material (specific radioactivity $84 \mathrm{mCi} / \mathrm{mmol}$, as supplied by Amersham International) in $2 \mathrm{ml}$ of the same buffer was passed through the column. D-Tryptophan was eluted with a total of $6 \mathrm{ml}$ of the borate buffer (elution was complete within $4-5 \mathrm{ml}$ ), and then the L-enantiomer was eluted with $3 \mathrm{ml} 0 \cdot 1 \mathrm{M}$-acetic acid. This eluate was neutralized with $\mathrm{NaOH}$, and was stored at $-20^{\circ}$ until it was required. The recovery of radioactivity in the L-tryptophan fraction was almost quantitative; $48 \%$ of the total radioactivity that was applied to the column as the racemic mixture was recovered in the acetic acid eluate.

\section{RESULTS}

Fig. 2 shows the production of ${ }^{14} \mathrm{CO}_{2}$ from the two positional isomers of $\mathrm{L}-\left[{ }^{14} \mathrm{C}\right]$ tryptophan that were used. There was significantly less ${ }^{14} \mathrm{CO}_{2}$ produced from $\mathrm{L}-\left[\right.$ methylene $\left.-{ }^{14} \mathrm{C}\right]$ tryptophan by animals that had been fed on the high-leucine diet. Both the total area under the curve and the height of the peak of ${ }^{14} \mathrm{CO}_{2}$ production were significantly lower than in control animals. As can be seen from Table 1, this was associated with a lower value of the first-order rate-constant for the decay of ${ }^{14} \mathrm{CO}_{2}$ production $(k)$, and hence a longer half-time of ${ }^{14} \mathrm{CO}_{2}$ production in the leucine-fed animals.

By contrast, animals receiving the high-leucine diet showed a significantly higher production of ${ }^{14} \mathrm{CO}_{2}$ from L-[benzene ring $\left.\mathrm{U}-{ }^{14} \mathrm{C}\right]$ tryptophan, with both a greater area under the curve and a higher peak of ${ }^{14} \mathrm{CO}_{2}$ production than for animals receiving the control diet. As can be seen from Table 1, this was associated with a significantly higher value of $k$ and a correspondingly shorter half-time for the production of ${ }^{14} \mathrm{CO}_{2}$ from this isomer when the animals were fed on the high-leucine diet.

\section{DISCUSSION}

Enzyme studies with tissue homogenates in this laboratory (Magboul \& Bender, 1983) have shown that L-leucine is a competitive inhibitor of kynureninase at concentrations of leucine of the same order of magnitude as occur in vivo. The same study also showed some evidence that kynureninase activity was depressed in vivo in animals fed on a high-leucine diet, since they excreted significantly more kynurenine than did animals receiving the control diet. The results reported here, of reduced production of ${ }^{14} \mathrm{CO}_{2}$ from $\left[\right.$ methylene $\left.{ }^{-14} \mathrm{C}\right]$ tryptophan by 


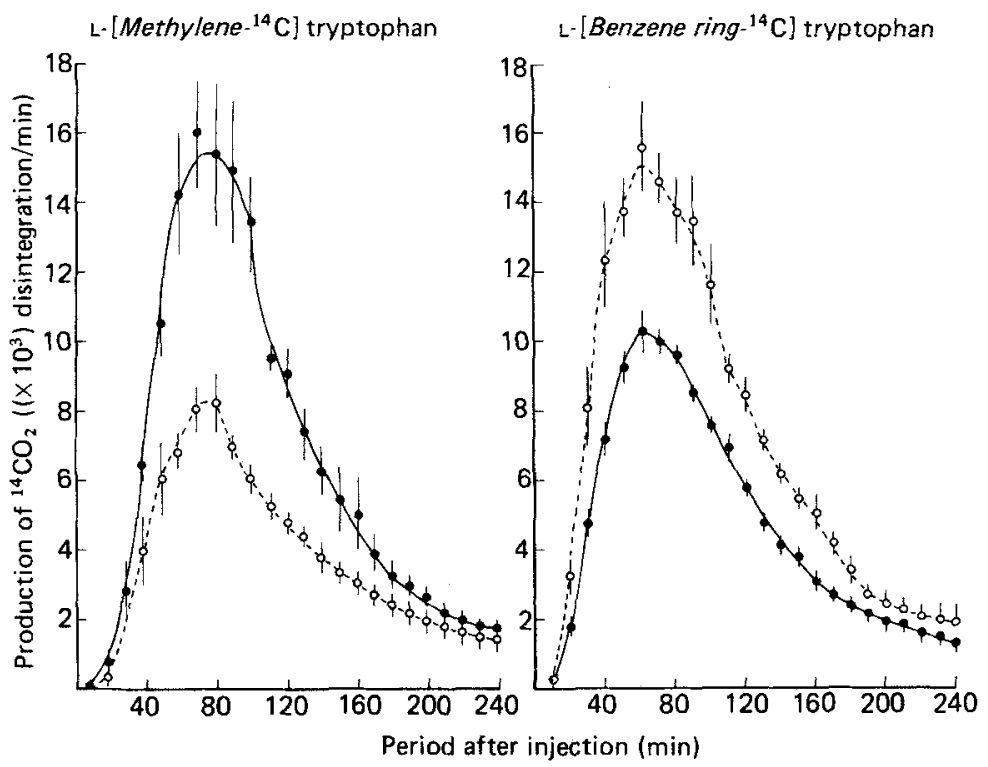

Fig. 2. The production of ${ }^{14} \mathrm{C}$-labelled carbon dioxide from [methylene- $\left.{ }^{14} \mathrm{C}\right]$ tryptophan and [benzene ring U-14 C]tryptophan by rats fed on a niacin-free diet with $(O)$ or without $(\bullet)$ the addition of $15 \mathrm{~g}$ $\mathrm{L}$-leucine $/ \mathrm{kg}$. Points are mean values with their standard errors, represented by vertical bars, for three animals per group.

animals fed on a high-leucine diet, confirm that there is indeed inhibition of kynureninase in vivo by a dietary excess of leucine.

Magboul \& Bender (1983) were unable to demonstrate an effect of leucine on the activity of picolinate carboxylase in tissue homogenates. However, both Ghafoorunissa \& Narasinga Rao (1973) and Krishnaswamy \& Bapu Rao (1978) have demonstrated an increase in the activity of this enzyme when rats were fed on a diet that provided a greater excess of leucine $(30 \mathrm{~g} / \mathrm{kg})$ than has been used here $(15 \mathrm{~g} / \mathrm{kg})$. The results reported here, an increase in the production of ${ }^{14} \mathrm{CO}_{2}$ from [benzene ring $\mathrm{U}_{-14}{ }^{14} \mathrm{C}$ tryptophan by animals receiving the high-leucine diet, confirm that the activity of picolinate carboxylase is increased by a dietary excess of leucine.

The production of ${ }^{14} \mathrm{CO}_{2}$ is not a direct consequence of the metabolism of either of the positional isomers of $\left[{ }^{14} \mathrm{C}\right]$ tryptophan that have been used in the present study. As can be seen from Fig. 1, the metabolism of [methylene $\left.{ }^{14} \mathrm{C}\right]$ tryptophan leads to the formation of $\left[{ }^{4} \mathrm{C}\right]$ alanine, which must undergo transamination to pyruvate and oxidative decarboxylation to acetyl-CoA before oxidation to yield respiratory ${ }^{14} \mathrm{CO}_{2}$. Acetyl-CoA is also, more directly, the product of the oxidation of [benzene ring $\left.\mathrm{U}-{ }^{14} \mathrm{C}\right]$ tryptophan after the action of picolinate carboxylase. Smith et al. (1980) observed a difference in the production of ${ }^{14} \mathrm{CO}_{2}$ from $\left[{ }^{14} \mathrm{C}\right]$ tryptophan by isolated rat hepatocytes depending on the metabolic state of the animals from which the cells were prepared; in liver from fed rats there was more lipogenesis from acetate and gluconeogenesis from pyruvate than in liver from fasted animals, where oxidation of acetate predominated. It is unlikely that any such effect is important in the present study; all the animals were in the same over-all metabolic state, having been allowed free access to food until 08.30 hours on the day of the experiment and, therefore, having been able to feed throughout the normal (nocturnal) feeding period of the rat. Furthermore, feeding the high-leucine diet caused reduced production of ${ }^{14} \mathrm{CO}_{2}$ from $\left[\right.$ methylene $\left.-{ }^{14} \mathrm{C}\right]$ tryptophan and increased production from [benzene ring $\left.\mathrm{U}-{ }^{14} \mathrm{C}\right]$ tryptophan, 
D. A. Bender

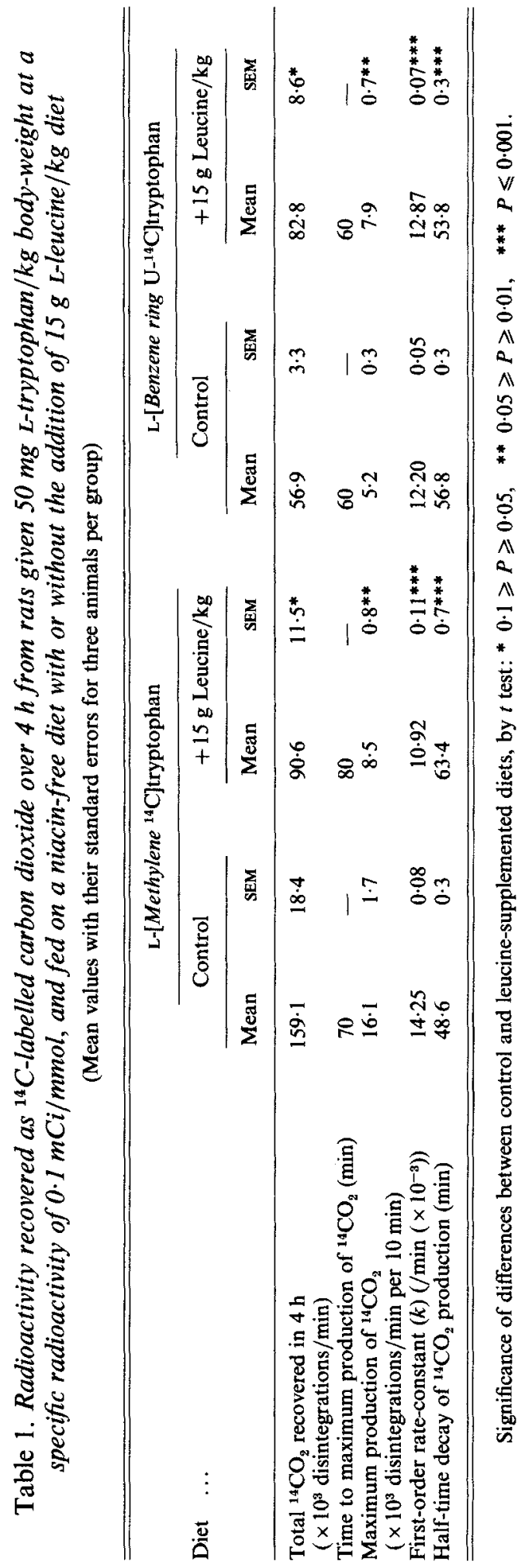


effects which cannot be accounted for by a change in acetate metabolism, since this would be the same for both substrates.

It is possible that a dietary excess of leucine has a more specific effect on the metabolism of alanine or pyruvate, and that this may contribute to the reduced production of ${ }^{14} \mathrm{CO}_{2}$ from [methylene $\left.{ }^{-14} \mathrm{C}\right]$ tryptophan in the leucine-fed animals. However, in view of the evidence that leucine is a competitive inhibitor of kynureninase in vitro, as well as the increased urinary excretion of kynurenine by animals fed on a high-leucine diet (Magboul \& Bender, 1983), it is most probable that the reduced production of ${ }^{14} \mathrm{CO}_{2}$ from [methylene${ }^{14} \mathrm{C}$ tryptophan by leucine-fed animals reflects a lower activity of hepatic kynureninase in these animals.

Increased activity of picolinate carboxylase will reduce the synthesis of nicotinamide nucleotides from tryptophan. Quinolinic acid, the immediate precursor of the nucleotides, is formed from acroleylaminofumarate (aminocarboxymuconate semialdehyde) by a nonenzymic cyclization. This means that significant amounts of quinolinic acid will be formed only when picolinate carboxylase is saturated with its substrate; quinolinic acid then accumulates in adequate amounts for a significant non-enzymic reaction to occur. An increase in the activity of the enzyme will reduce the amount of acroleylaminofumarate that is available for this. A number of studies have shown that in different species of animals (Nishizuka \& Hayaishi, 1963; Ikeda et al. 1965) and in response to various experimental manipulations (Sanada \& Miyazuki, 1980; Sanada et al. 1980) there is an inverse relationship between the activity of picolinate carboxylase and the synthesis of nicotinamide nucleotides from tryptophan.

Reduced activity of kynureninase will also affect the relative amounts of tryptophan either undergoing total oxidation as a result of picolinate carboxylase activity or entering the pathway leading to nicotinamide nucleotides, since there will be a lower rate of formation of acroleylaminofumarate and, therefore, a lower extent of saturation of picolinate carboxylase, when kynureninase is inhibited. This means that a greater proportion of tryptophan will be oxidized to $\mathrm{CO}_{2}$ than when the activity of kynureninase is higher, and there is a greater flux of metabolites through the pathway. In the present study, there was a greater total amount of tryptophan undergoing total oxidation, as shown by the greater area under the curve and the greater peak height of ${ }^{14} \mathrm{CO}_{2}$ production from [benzene ring $\left.\mathrm{U}-{ }^{14} \mathrm{C}\right]$ tryptophan in the animals receiving the high-leucine diet. This must be interpreted as indicating a considerable increase in the activity of picolinate carboxylase, in view of the inhibition of kynureninase under the same conditions and, hence, the lower flux of metabolites through the pathway; not only was a greater proportion of tryptophan being oxidized by this pathway, but a greater total amount.

From the results reported here, and those of Magboul \& Bender (1983), Ghafoorunissa \& Narasinga Rao (1973) and Krishnaswamy \& Bapu Rao (1978), it seems that the pellagragenic action of excess dietary leucine can be accounted for by, and attributed to, both reduced activity of kynureninase and increased activity of picolinate carboxylase. Under these conditions, and especially when the total amount of tryptophan available from the diet is low, a very much greater proportion of such tryptophan as is available will be metabolized to acetyl-CoA, and hence to $\mathrm{CO}_{2}$, and less will be available for synthesis of nicotinamide nucleotides. Although sorghum contains a relatively large amount of niacin, most of this is chemically bound and, therefore, biologically unavailable (Magboul \& Bender, 1982), and so inhibition of the synthesis of nicotinamide nucleotides from tryptophan by the relative excess of leucine that is present in sorghum proteins (Gopalan \& Srikantia, 1960) may be an important factor in the aetiology of pellagra in man. 


\section{REFERENCES}

Bender, D. A., Magboul, B. I. \& Wynick, D. (1982). British Journal of Nutrition 48, 119-127.

Ghafoorunissa \& Narasinga Rao, B. S. (1973). Biochemical Journal 134, 425-430.

Gopalan, C. \& Srikantia, S. G. (1960). Lancet i, 954-957.

Ikeda, M., Tsuji, H., Nakamura, S., Ichiyama, A., Nishizuka, Y. \& Hayaishi, O. (1965). Journal of Biological Chemistry 240, 1395-1401.

Krishnaswamy, K. \& Bapu Rao, S. (1978). British Journal of Nutrition 39, 61-64.

Magboul, B. I. \& Bender, D. A. (1982). Proceedings of the Nutrition Society 41, 50A.

Magboul, B. I. \& Bender, D. A. (1983). British Journal of Nutrition 49, 321-329.

Nishizuka, Y. \& Hayaishi, O. (1963). Journal of Biological Chemistry 238, 3369-3377.

Sanada, H. \& Miyazaki, M. (1980). Journal of Nutritional Science and Vitaminology 26, 617-627.

Sanada, H., Miyazaki, M. \& Takahashi, T. (1980). Journal of Nutritional Science and Vitaminology 26, $449-459$. Smith, S. A., Carr, F. P. A. \& Pogson, C. I. (1980). Biochemical Journal 192, 673-686.

Stewart, K. K. \& Doherty, R. F. (1973). Proceedings of the National Academy of Sciences USA 70, $2850-2852$. 